\title{
SINGLE CENTER EXPERIENCE IN MANAGEMENT OF ACUTE MESENTERIC ISCHEMIA AND THE IMMEDIATE OUTCOME FOLLOWING SURGICAL SALVAGE
}

\author{
SHABIR AHMAD, AHMAD NAEEM AKHTAR, NAZIA FAROOQ, AJMAL FAROOQ, \\ FARMAN ALI, QASIM FAROQ \\ Department of Surgery, Postgraduate Medical institute/Ameer-u-din Medical College/ \\ Lahore General Hospital Lahore.
}

\begin{abstract}
Background: Acute Mesenteric Ischemia is a rare condition with an incidence of 5/100,000. Occlusive subtype has the better outcome if early presentation and urgent surgical intervention is made.

Objectives: To determine the role of early intervention. To improve the outcome in acute mesenteric ischemia.

Methods: The study was conducted at Lahore General Hospital, Lahore from Jan, 2016 to Jan, 2018. During this time period 12 patients were enrolled in the study fulfilling the inclusion and exclusion criteria.

Mean age was 58 years and all were male (range $45-75$ years). All 12 patients were symptomatic at presentation with severe abdominal pain (94.3\%), abdominal distension (63.6\%) and vomiting (40.4\%) alone or in combination. 7 patients (58.3\%) presented within 24 hours from the onset of symptoms whereas 5 patients (41.6\%) presented late. All patients who presented within 24 hours of onset of symptoms survived whereas all patients who presented after 24 hours from the onset of symptoms could not survive. The mortality rate for early presenters was zero $\%$ while for late presenters it was $100 \%$. On whole the mortality rate for our 12 patients with Acute Mesenteric Ischemia was $41.7 \%$.

Conclusion: Acute mesenteric ischemia patient presentation within 24 hours from the onset of symptoms with early diagnosis and surgical intervention had much better outcome.
\end{abstract}

Keywords: Acute mesenteric ischemia, early presentation, early diagnosis, early surgical intervention.

How to cite this article: Hussain Y, Anjum R, Munawar N, Fatima Z, Naz S, Mehmood A. Single center experience in management of acute mesenteric ischemia and the immediate outcome following surgical salvage. Pak Postgrad Med J 2020;31(4): 201-203

This is an Open Access article distributed under the terms of the Creative Commons Attribution License (http://creativecommons.org/licenses/by/3.0), which permits unrestricted use, distribution, and reproduction in any medium, provided the original work is properly cited.

DOI: http://doi.org/10.51642/ppmj.v31i04.410

Correspondence to: Shabir Ahmad,

Assistant Professor,

Department of Surgery, Postgraduate Medical

institute/Ameer-u-din Medical College/Lahore General

Hospital Lahore, Pakistan.

\section{Email:drshabbirch@yahoo.com}

\section{INTRODUCTION}

Mesenteric ischemia is mostly an unusual presentation and the patients present with severe abdominal pain which is mostly out of proportion. ${ }^{1}$

Mesenteric ischemia is divided into "acute" and "chronic". Acute mesenteric ischemia has occlusive and non-occlusive subtypes whereas occlusive can be due to both arterial and venous obstruction. ${ }^{2-4}$
Even with the recent advancements in diagnostics tools, the prognosis still depends most importantly on rapid clinical assessment followed by early intervention and decision making ${ }^{5-9}$.

Patients with acute mesenteric ischemia have vague clinical presentations with significantly out of proportion abdominal pain, indecisive peritonitis, and insignificant tachycardia along with any of the co morbidities like ischemic heart disease, hypertension and diabetes in association with smoking, old age, hyperlipidemias etc. ${ }^{10}$

The clinical outcome of these patients is dismal which is frequently overlooked and often a fatal condition $^{3-5}$. The incidence is 5 per 100,000 people in the developed world ${ }^{6}$ and thromboembolism is its leading cause. Its incidence is increasing ${ }^{3}$ and has an internationally reported mortality rate of up to $80 \%{ }^{1-5}$. The clinical outcome of these patient is hugely 
dependent on Time duration for their presentation i.e. Early Vs Late. ${ }^{8-9}$

In the past, it was common to immediately close the abdomen on identification of mesenteric ischemia and was advised "to let the nature decide its fate". It was quite demoralizing for the patient, relatives and the surgeons as well.

\section{METHODS}

Our study was conducted in Accident and Emergency Department of Lahore General Hospital, Lahore from January 2016 to January 2018. It was hypothesized that early presentation and early surgical exploration can improve the patient outcome.

Patients were identified for Early Exploration on the basis of history and character of pain with a High Index of Suspicion based on presence of co morbidities (Diabetes Mellitus, Hypertension, Cardiac Disease, History of Thromboembolic events). All patients were operated within 90 minutes of presentation in emergency. Resection of Diseased segment and end to end anastomosis with absorbable Vicryl 3/0 single layer interrupted extra mucosal sutures. All patients were given Intravenous Heparin and Papaverine. Clotting profiles were monitored along Hemoglobin and platelet counts. Patients with segmental mesenteric vascular occlusion were included in the study whereas Patients who had global mesenteric ischemia involving the complete distribution of Superior Mesenteric Artery and with mechanical obstruction (volvulus, strangulated hernia and adhesion bands, Intussusception) causing bowel ischemia were excluded from the study. Clopidogrel was advised in follow up.

In total, 12 patients fulfilled our criteria and were included in this study.

Rationale for use of papaverine: It is an Alkaloid derivative of Morphine and is used as an Antispasmodic. According to Acute mesenteric ischemia: guidelines of the World Society of Emergency Surgery ${ }^{8}$ (2017), Papaverine can be administered into Superior Mesenteric Artery in cases of Acute Embolus, and should be used as an Intravenous Infusion in all cases of Thrombosis and Non-Occlusive Mesenteric Ischemia.

\section{RESULTS}

Twelve patients fulfilling our criteria were included in the study with their clinical assessment and early decision making by the consultant. These patients were managed for Acute Mesenteric Ischemia from 2016 to 2018 in emergency department. Mean age was 58 years and all were male (range 45 - 75 years). All 12 patients were symptomatic at presentation with severe abdominal pain (94.3\%), abdominal distension (63.6\%) and vomiting $(40.4 \%)$ alone or in combination. 7 patients $(58.3 \%)$ presented within 24 hours from the onset of symptoms whereas 5 patients (41.6\%) presented late which was more than 24 Hours from the onset of symptoms. Early assessment was made followed by early exploration. All patients who presented within 24 hours of onset of symptoms survived whereas all patients who presented after 24 hours from the onset of symptoms could not survive. The mortality rate for early presenters was zero $\%$ while for late presenters it was $100 \%$. On whole the mortality rate for our 12 patients with Acute Mesenteric Ischemia was $41.7 \%$ (5 out of 12 ).

\section{DISCUSSION}

In our study conducted at Lahore general hospital reported an average age of 58 years whereas stiger-serra et al in 1988 had shown an average age of 71 years. None of other scientists has mentioned the average age in their studies. Our study has shown significant lower age for the disease in comparison to the study which is alarming for the healthcare providers.

Our study has reported that all patients were of male gender which is not mentioned in any of the studies available.

Our study has reported mortality rate of $41.7 \%$ which is comparable to the surgeons like Stiger-Serra et al who claimed mortality rates of $46 \%$ amongst these patients after surgical intervention. Another surgeon named A W Bradbury in 1995 has narrated that surgery is the only lifesaving option for the patients of acute mesenteric ischemia. In year 2001, J Hajovan et al has reported the mortality rates of $60 \%$ amongst these patients and advocated surgery as the only available option. Similarly, Sungho Lim et al in 2019 reported the benefits of early intervention both surgical as well as endovascular.

Study has claimed better outcomes if patients present early to health care establishments and early intervention is made, we had excellent results with 100 $\%$ survival amongst these patients. ${ }^{11-12}$ (58.3\%) presented within 24 hours from the onset of their symptoms and they all survived the surgical intervention whereas $5(41.6 \%)$ presented late to the hospital and could not survive. Similarly, J Hajovan et al in 2001 has advised early diagnosis and immediate surgical intervention for better survival rates. This is supported by Stoney et al ${ }^{8-9}$ who reported increased mortality if patient is operated after 30 hours of onset of symptoms

All these patients were Heparinized with monitoring till the gut motility followed by Anti platelet drug usage. Routine usage of Intravenous Papaverine and Heparin is recommended. ${ }^{13-15}$

\section{CONCLUSION}

If patients with acute mesenteric ischemia presents within 24 hours from the onset of symptoms followed by early diagnosis and surgical intervention is made, we can have much better outcomes. 


\section{ETHICAL APPROVAL}

The study was approved from Institutional Review Board of Postgraduate Medical Institute/Ameer ud Din Medical College/Lahore General Hospital, Lahore, Pakistan, vide reference No. AMC/PGMI/LGH/Article/Research No/ 00-16120, dated October 24, 2020.

\section{REFERNCES}

1. Karthik G, Paul F. (2020). Review Article; Mesenteric Ischemia. Current Gastroenterology Reports Vol 22, article 17

2. Chat V Dang, John Geibel, Mark Su, Daniel K Nishijima; (2020). Acute Mesenteric ischemia https://emedicine. medscape.com/article/189146-overview

3. Heys SD, Brittenden J, Crofts TJ; Acute mesenteric ischaemia: the continuing difficulty in early diagnosis. Postgrad Med J. 1993;6948-6951

4. van Petersen AS, Kolkman JJ, Meerwaldt R, Huisman AB, van der Palen J, Zeebregts CJ, et al. Mesenteric stenosis, collaterals, and compensatory blood flow. J Vasc Surg. 2014; 60(1):111-119,

5. Robin M Lawson., ( 2018) Mesenteric Ischemia., Crit Care Nurs Clin North Am; 30(1): 29-39 doi: 10.1016/j.cnc.2017.10.003. Epub 2017 Nov 20.

6. Sitges-Serra A, Mas X, Roqueta F, Figueras J, Sanz F; Mesenteric infarction: an analysis of 83 patients with prognostic studies in 44 cases undergoing a massive smallbowel resection. BrJ Surg. 1988;75544-75548

7. Clair DG, Beach JM. Mesenteric Ischemia. N Engl J Med. 2016;374(10):959-968.

8. Stoney,R.J., Cunningham, C.G; Acute mesenteric ischemia. Surgery. 1993;114489- 114490

9. Lock G;. Acute intestinal ischaemia. Best Pract Res Clin Gastroenterol.2001;1583-1598

10. Geoff rey D, Rubin (2012). CT \& MR Angiography comprehensive vascular assessment LipinOH Williams C William p318 ISBN 9781469801834.
11. Sungho Lim, Pegge M Halandras, Carlos Bechara, Bernadette Aulivola, Pau Crisosotomo., (2019). Contemporary management of acute mesenteric ischemi in the endovascular Era., Vasc Endovascular Surg., Jan 53(1): 42-50

12. Bradbury AW, Brittenden J, McBride KRuckley CV; Mesenteric ischaemia: a multidisciplinary approach. Br J Surg. 1995;821446- 821459

13. Boley, S. J., Sprayregan, S., Siegelman, S. S., \& Veith, F. J. (2018). Initial results from an aggressive roentgenological and surgical approach to acute mesenteric ischemia. Surgery, 82(6), 848-855.

14. Bhagirath Desai A, Sandeep Shah D, Jagat Bhatt C, Umesh Vaishnav K, Salvi B. Measurement of the distance and angle between the aorta and superior mesenteric artery on CT scan: values in Indian population in different BMI categories. Indian J Surg. 2015;77(Suppl 2):614-617

15. Hajovan B, Robert H. (2001) Chronic splanchnic ischaemia. B Pr Re Cl Gastr. 15(1) 99-119

16. Karkkainen JM, Acosta S. Acute mesenteric ischemia (part I) - incidence, etiologies, and how to improve early diagnosis. Best Pract Res Clin Gastroenterol. 2017;31(1):15-25.

\section{AUTHOURS CONTRIBUTIONS}

SA: Manuscript Writing

ANA, FA: Data Collection

NF, QF: Data Analysis

AF: Critical Analysis

FA: Data Collection 